\title{
Noctilucent clouds observed from the UK and Denmark - trends and variations over 43 years
}

\author{
S. Kirkwood ${ }^{1}$, P. Dalin ${ }^{1}$, and A. Réchou ${ }^{2}$ \\ ${ }^{1}$ Swedish Institute of Space Physics, Box 812, 98128 Kiruna, Sweden \\ ${ }^{2}$ Laboratoire de l'Atmosphère et des Cyclones, Université de la Réunion - Faculté des Sciences et Technologies, BP 7151 - \\ 15 avenue René Cassin - 97715 ST DENIS Messag Cedex 9, Ile de la Réunion, France
}

Received: 11 May 2007 - Revised: 15 August 2007 - Accepted: 15 August 2007 - Published: 28 May 2008

\begin{abstract}
The combined UK/Denmark record of noctilucent cloud (NLC) observations over the period 1964-2006 is analysed. This data set is based on visual observations by professional and voluntary observers, with around $40 \mathrm{ob}-$ servers each year contributing reports. Evidence is found for a significantly longer NLC season, a greater frequency of bright NLC, and a decreased sensitivity to 5-day planetary waves, from 1973-1982, compared to the rest of the time interval. This coincides with a period when the length of the summer season in the stratosphere was also longer (defined by zonal winds at $60^{\circ} \mathrm{N}, 30 \mathrm{hPa}$ ). At NLC heights, lower mean temperatures, and/or higher water vapour and/or smaller planetary wave amplitudes could explain these results. The time series of number of NLC nights each year shows a quasi-decadal variation with good anti-correlation with the $10.7 \mathrm{~cm}$ solar flux, with a lag of 13-17 months. Using multi-parameter linear fitting, it is found that the solarcycle and the length of summer in the stratosphere together can explain $\sim 40 \%$ of the year-to-year variation in NLC numbers. However, no statistically confidant long-term trend in moderate or bright NLC is found. For NLC displays of moderate or greater intensity, the multi-parameter fit gives a trend of $\sim 0.08$ nights $(0.35 \%)$ per year with a statistical probability of $28 \%$ that it is zero, or as high as 0.16 nights $(0.7 \%)$ per year. There is a significant increasing trend in the number of reports of faint or very faint NLC which is inconsistent with other observations and may be due changes in observing practices.
\end{abstract}

Keywords. Atmospheric composition and structure (Middle atmosphere - composition and chemistry) - Meteorology and atmospheric dynamics (Middle atmosphere dynamics)

Correspondence to: S. Kirkwood

(sheila.kirkwood@irf.se)

\section{Introduction}

Noctilucent clouds (NLC) are the highest altitude clouds in the Earth's atmosphere. They lie at $\sim 82-85 \mathrm{~km}$ heights and are seen at high latitudes (mainly above $50^{\circ}$ ) during summer. They are seen from the ground, by the naked eye, as silvergrey patterns against the twilight sky, lit up from below by the sun below the horizon. As described in the review by Fogle and Haurwitz (1966), the earliest well documented reports of NLC are from 1884, when many observers were watching the twilight sky to see the dramatic results of the dust thrown into the atmosphere by the eruption of Krakatoa in the previous year. However, NLC-like features in a painting by W. Dyce in 1836 or 1837, showing a twilight scene from Edinburgh in Scotland $\left(56^{\circ} \mathrm{N}\right)$, may point to earlier observations (Gadsden, 2002a), before the special nature of these clouds was recognized in the late 19th century.

Many efforts were made to document and to understand NLC in the 20th century. These are expertly summarized by Fogle and Haurwitz (1966) and by Gadsden and Schröder (1989). No attempt is made to make a complete review of NLC science in this short report, only the most important characteristics are mentioned, which are of relevance for the present study, which concerns possible trends over the last 43 years. It is by now well established that NLC consist of water ice which forms due to the extremely cold temperatures which prevail close to the mesopause $(\sim 85-90 \mathrm{~km}$ height), at high latitudes, during the summer. These very cold temperatures, as low as 120-140 K, are low enough that the air is super-saturated with respect to water vapour even though the amount of water vapour in the atmosphere is very small (a few ppm). Provided that there are sufficient condensation nuclei (for example provided by meteoric dust), ice will form in these conditions and the ice particles can grow to sufficient size (a few $10 \mathrm{~s}$ of $\mathrm{nm}$ ) to make visible clouds within a few hours. This is most likely to start at the height where the temperature is lowest, around $85 \mathrm{~km}$. As they grow they will start

Published by Copernicus Publications on behalf of the European Geosciences Union. 
to fall until they reach heights around $82 \mathrm{~km}$ where the temperature has risen enough that the air is no longer saturated. There the ice particles will evaporate within a few minutes. (For detailed modelling of the life cycle of NLC particles, see e.g. von Zahn and Berger, 2003.)

In recent years, it has become of interest to look for trends in atmospheric characteristics, as possible diagnostics of anthropogenic changes to the atmosphere. Occurrence statistics of noctilucent clouds offer a potential diagnostic for changes in temperature or water vapour at the high-latitude, summer mesopause. Temperature changes might be expected to result from changes in long-wave radiation due to increasing greenhouse gas concentrations, or from changes in the largescale atmospheric circulation, which is the main cause of the extremely low temperatures at the summer mesopause (see e.g. Andrews et al., 1987). Changes in water vapour could arise from changes in the source gases for water vapour in the upper atmosphere (water and methane from the troposphere). For a detailed study of NLC sensitivity to water vapour changes see e.g. von Zahn et al. (2004).

In a series of papers starting in 1985, results based on observations from "NW Europe" were published which seemed to show a dramatic increase in NLC occurrence rates - almost a doubling over 2 decades from the 1960s to the 1980s (Gadsden, 1985, 1990, 1998). Gadsden's work and the lack of scientifically documented NLC observations before 1885 , have been widely cited as evidence for anthropogenic changes in the atmosphere (e.g. Thomas et al., 1989; Gore, 1992). However, re-examination of the published summaries of NLC observations from "NW Europe" showed that the reported increase was in error, and resulted from the inadvertent inclusion of observations from a new geographic area (Finland) in the latter part of the time interval (Kirkwood and Stebel, 2003; Gadsden, 2002b; M. Gadsden, personal communication, 2002). If there was any trend in the data, it seemed to be very small. However, analysis of observations from satellites has suggested that there may be an increase in the relative proportion of brighter clouds by $\sim 15 \%$ over the years 1978-2002 (DeLand et al., 2003). (Note that NLC observed from satellites are generally termed polar mesospheric clouds, PMC, and are seen at higher latitudes than NLC observed from the ground.) Also Shettle et al. (2002), found an increase in the numbers of the brightest PMC between 1983 and 1996, using satellite observations. In the most comprehensive analysis of satellite data so far, DeLand et al. (2007) found a $17 \%$ increase in northern hemisphere PMC albedo for the period 1979-2006. In contrast, recent analysis of ground-based NLC observations from Moscow (1962-2005) and Denmark (1983-2005) has found no evidence for statistically significant increases in occurrence frequency or brightness (Dalin et al., 2006). The uncertainties in the trend analysis from the latter measurements are, on the other hand large, due to the small number of observations available from just two locations, the latter varying between 5 and 20 nights per year from Moscow, and 3-14 from Denmark.
It is also clear from the historical record that NLC occurrence rates have varied by large factors from year to year, during the late 19th and early 20th centuries, long before anthropogenic inputs are likely to have had any effect (Fogle and Haurwitz, 1966). These natural fluctuations also need to be better documented and understood.

Three further important characteristics of NLC have been found by recent research, which can affect the interpretation of occurrence statistics. The first is that it has been shown that both NLC and the closely related radar phenomenon, polar mesosphere summer echoes (PMSE), are affected by planetary waves (Kirkwood and Réchou, 2000; Kirkwood et al., 2002; Kirkwood and Stebel, 2003; Merkel et al., 2003). This means that NLC can be affected by changes in planetary wave phase from place to place (stationary waves) and in time (travelling waves). The planetary waves most evidently affecting NLC have zonal wave number 1, which means that optimal conditions for NLC on one side of the globe will occur simultaneously with the least favourable conditions at the opposite side. The second important characteristic of NLC is that there are substantial changes on longitude distances even much less than the wavelength of those planetary waves. This is evidenced by the study of Dalin et al. (2006) where it is shown that, in most years, only $10-40 \%$ of NLCpositive nights in Moscow are also recorded as NLC-positive in Denmark, only $1600 \mathrm{~km}$ to the west. Note that those datasets include information on weather conditions also on NLCnegative nights, so that the comparison is based on nights when viewing conditions were good at both sites. The reasons for this spatial variability are so far not established - it could be due to smaller-scale waves affecting the temperature or to variability in the availability of water vapour due to the history of different air masses.

It was well recognised early on that NLC occurrence increases with increasing latitude, particularly towards the end of the season (e.g. Fogle and Haurwitz, 1966; Paton, 1971; Simmons and McIntosh, 1983), so that statistical studies to look for changes in occurrence rates must be based on observations made throughout from the same geographical region, restricted in both latitude and longitude. The third important NLC characteristic is that there is a strong daily variation. This has been diagnosed by round-the-clock lidar measurements (Fiedler et al., 2005), which show (at $69^{\circ}$ N) NLC roughly twice as often between 00:00-06:00 LT (local solar time), compared to 10:00-20:00 LT, for all detectable NLC. The ratio increases to a factor 8 for the brightest NLC. As a result, NLC observations which can be used to look for longterm trends, should be made at a constant local time. This favours observations from ground-based networks, since the viewing conditions naturally restrict the observations to the hours close to local midnight. The LT variation is a problem for the studies based on satellite data, where the LT of the observations changes over the years, particularly when a series of different satellites is used. DeLand et al. (2007) have attempted to make corrections for the LT variations but 
the latter are not well determined by the available measurements, so that any correction applied has some uncertainty.

NLC observations by observers at typically 30-40 different locations, covering the UK and Denmark, have been made and collected systematically for, so far, 43 summer seasons since 1964. This is a reasonably large, but still welldefined and restricted geographical region (confined in both latitude and longitude, with constant limits over time). This is the biggest database available in terms of the number of NLC occurrences documented (on average 28 nights/year). The Moscow dataset (Romejko et al., 2003; Dalin et al., 2006) is slightly longer (from 1962-present) but it is from essentially a single location so that the number of possible observing nights each year is restricted by bad weather (on average 12 NLC occurrences per year have been reported, with $43 \%$ of nights with good enough weather for NLC observations). The UK/Denmark database includes many sites within a region where the weather is highly changeable, both from day to day and from place to place. If the Moscow observed occurrence rate is corrected by the weather factor, it seems that the true occurrence rate there should be close to 28 nights per year, i.e. the same as the UK/Denmark database. This suggests that the spread of the UK/Denmark database does indeed largely compensate for the weather factor (unless the real occurrence rates are very different in the two locations), although this is an uncertainty which must be considered in any interpretation of results. An analysis of possible trends in the UK/Denmark data set, properly restricted in geographical coverage, has not previously been published in the refereed literature (although part of the Danish data set is included in Dalin et al., 2006). Here such an analysis is presented, covering the 43 year period 1964-2006.

\section{Description of the data set}

Noctilucent cloud (NLC) observations from the UK and Denmark have been collected and documented, with varying degrees of detail, since 1964. Starting in 1964, regular observations were collected from 15 meteorological stations throughout the UK, by 15 other observers in the UK, and by 2 in Denmark. These, observations up to 1982 were collected, synthesised and summarized in reports by the Balfour Stewart Laboratory, and later by the Meteorology Department, of Edinburgh University in Scotland (Paton, 19651973; McIntosh and Halliwell, 1974-1983). The exact nature of the observation schedule is not described in the first reports, but the detail of information in the summaries, and details in later reports (McIntosh and Halliwell, 1977) indicate that NLC observations were simply added to the usual hourly "synoptic" observations made at the meteorological stations (which include visual inspection of the sky to make estimates of tropospheric cloud cover). The meteorological stations made hourly reports on both the presence and absence of NLC from 26 May to 7 August, although they clearly reported NLC at earlier and later dates also, if they occurred. Other observers reported mainly positive observations only. The exact numbers of observers in each category is not documented in the published summaries for the years between 1965-1975. However, by 1976, 28 UK meteorological stations and observers at 8 further UK locations were contributing, plus 2 observers from Denmark. It is clear from the tables summarizing the NLC reports that observations from the whole of the UK, and from at least one site in each of Ireland and Denmark were included throughout the period. Observations from other locations e.g. Holland, Iceland, Greenland, Germany, Norway, Sweden, Finland, aircraft, weather ships, Falkland Is. are mentioned occasionally in the reports but they are not included in a systematic way. The main characteristics of the observations up to 1982 are summarized by Simmons and McIntosh (1983).

In 1983 the Auroral section of the British Astronomical Association took over the task of collecting NLC observations, and the routine hourly observations were discontinued at almost all of the UK meteorological stations. However, 26 observers around the UK (including 12 meteorological or air-force stations), and 2 in Denmark continued to report NLC, when they were observed (Gavine, 1984). Between 1983 and 2000, reports have been collected and summarised by Gavine (1984-1993, 1996, 2000, 2006). During this period the number of UK meteorological (including air-force) stations contributing each year decreased from 12 to 2 . The number of voluntary observers in the UK is hard to judge, since they could be recorded only when they delivered a positive report. This count varied between 15 in years when NLC were rare (1992) to at least 40 in years when NLC were common (1989, 1998-2000). Between 2 and 5 observers in Denmark contributed throughout 1993-2000, however it is not clear if there were reports from Ireland throughout the period. Again, observations from other countries were sometimes included.

NLC observation reports from an open network of unpaid observers in the UK and North West Europe, including many of those contributing to the earlier work described above, continue to be collected by the Auroral Section of the British Astronomical Association. They are also often reported to the dedicated website maintained by T. McEwen in the UK (http://www.nlcnet.co.uk/), where they have been archived since 1996.

In order to preserve, as far as possible, the same geographical coverage of observing sites, the analysis here is restricted to NLC observed from the UK (excluding northern Ireland) and from Denmark. The geographic coverage of the UK observing network up to 1982 stretched from the south of England $\left(50.5^{\circ} \mathrm{N}\right)$ to the Shetland Islands north of Scotland $\left(61^{\circ} \mathrm{N}\right)$, and from the Outer Hebrides of Scotland in the west $\left(7.5^{\circ} \mathrm{W}\right)$ to the eastern limit of the UK which is around $0^{\circ} \mathrm{E}$. From 1983 onwards the geographical spread in the UK reduced slightly but by 1999 still extended from $59^{\circ} \mathrm{N}$ (Fair Isle) to $51^{\circ} \mathrm{N}$ (Taunton and Crawley), and as far west as 

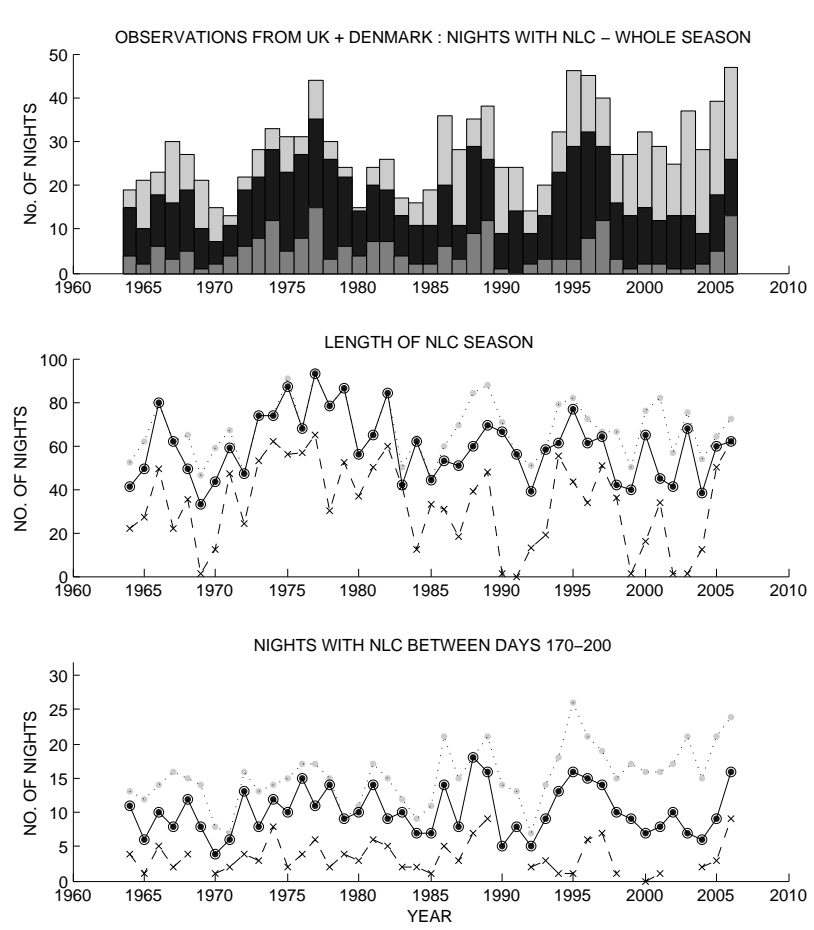

Fig. 1. Year-by-year characteristics of the UK/Denmark noctilucent cloud record. Top panel shows the number of nights each year when NLC were reported, for the whole season. Middle panel shows the length of the NLC season (the number of days between the first and last reported sightings). Bottom panel shows the number of nights with NLC reported during the core period of the season, the 30 nights between days 170-200 (20 June-20 July, 1 day earlier in leap years). Numbers are for all NLC reported (light gray, dotted lines), for a subset of reports where nights with only faint or very faint NLC are excluded (black, solid lines), and for nights when bright or very bright displays were reported (dark gray or crosses with dashed lines). The different histograms in the top panel are overlaid.

Ullapool $\left(5^{\circ} \mathrm{W}\right)$. The most eastward observations throughout have been (and still are) provided by the Danish observers, mostly from close to $10^{\circ} \mathrm{E}$, but also from the island of Bornholm $\left(14.5^{\circ} \mathrm{E}\right)$. However, the spread in latitude of the Danish observations is small, between $55^{\circ} \mathrm{N}$ and $57^{\circ} \mathrm{N}$.

The primary sources of data used here are the published summaries of the observations from 1964-2000 as mentioned above. Between 1993 and 2000, the format of the published summaries does not allow an unambiguous identification of observations from the UK or Denmark on all occasions. This information has been added by reference to the website mentioned above, from detailed lists provided by M. Gadsden (personal communication, 2001), and by O. Hansen and H. Andersen in Denmark (private communication, 2007), and by reference to the archives deposited by the British Astronomical Association in the Balfour Stewart Archive at the Aberdeen University library. For the years
2001-2006, preliminary lists have been compiled based on the observations reported to the website (http://www.nlcnet. co.uk/), and detailed lists collected by the British Astronomical Associations and by the Danish observers mentioned above (2001-2006).

Observers generally provide an estimate of the brightness of the NLC display, as very faint, faint, moderate, bright or very bright. Since there is a fair degree of inhomogeneity in the database, with a mixture of paid and voluntary observers, who vary over time, there is no quantitative use made of the brightness estimates. It is used only to make a 3-stage sorting of the data into "very faint or faint", "moderate", or "bright or very bright". "Weak" is taken to mean the same as faint, "brilliant" the same as very bright. The brightest estimate reported for each night is used, and an assumed "moderate" category when no estimate of brightness was recorded. NLC listed as "possible" or "suspected" are not included. A complete list of nights with positive identification of NLC, and maximum brightness, from observers in the UK or Denmark, compiled in this way, is included as an online supplement to this paper (http://www.ann-geophys.net/ 26/1243/2008/angeo-26-1243-2008-supplement.zip). However, it should be emphasised that much more detail of the observations is available in the annual summaries listed in the references, and in the Balfour Stewart Archive at Aberdeen University, including exact times and locations of observations and many photographs. Positive NLC nights are recorded only when NLC are reported by at least two independent observers, or as confident sightings by a single experienced observer.

There is no obvious effect of the change from mainly "professional" observers up to 1982 to mainly "amateur" observers in the later years. The statistics are based on nights of NLC, not individual reports, and NLC are usually reported by both amateur and professional observers on the same night, thus minimising the likely effect. The exception is the years 1983-1985 when the total number of observers was much reduced, the highest latitudes were not covered, and notably fewer NLC reports were registered, particularly late in the season.

\section{Cycles and trends}

Figure 1 summarizes the main characteristics of the database. The uppermost panel shows the number of nights each year when NLC were reported. The next panel shows the length of the NLC season (the number of days between the 1st and last reported sightings). The lowest panel shows the number of nights with NLC reported during the core period of the season, the 30 nights between days 170-200 (20 June-20 July, 1 day earlier in leap years). In each panel, characteristics for three subsets of the data are shown: all NLC reported (light gray, dotted lines), a subset of reports where nights with only faint or very faint NLC are excluded (black, solid lines), and 
for nights when bright or very bright displays were reported (dark gray or crosses with dashed lines). By visual inspection, it is immediately apparent that there is no obvious trend in any of the panels for the non-faint NLC. When the faint NLC are included, there is slight increasing trend in the number of NLC reported, both for the whole season and for the core period, but not in the length of the season. So the trends in total NLC are due to increasing numbers of reports of faint or very faint NLC, within a season of variable length, but without any obvious trend. The increase in reports of faint NLC could be a sign that such NLC really are increasing, but they could also be due to increasing skill among the observers in identifying faint NLC.

In order to look more carefully at this possibility, and to check more quantitatively for possible trends and their statistical uncertainties in the data, the other variations in the time series, which are also clear from Fig. 1, must first be considered. There are plainly substantial increases and decreases from year to year in all of the parameters shown. The variation in the total number of nights each year could be described as quasi-periodic, with a period around 10 years. This is less apparent in the core period, and not noticeable at all in the length of the season.

\subsection{Length of the NLC season}

Figure 2 looks in more detail at the length of the season. It shows start and end dates for the NLC season, and their relation to the start and end of the summer circulation in the stratosphere below. Summer in the high-latitude stratosphere is defined here as the period when the zonal-mean zonal-wind at the $30 \mathrm{hPa}$ pressure level $(\sim 30 \mathrm{~km}$ altitude) is westward, rather than eastward. This has been determined using the ERA-40 (1964-August 2002) and operational (September 2002-2006) global meteorological analyses from the European Centre for Medium Range Weather Forecasting (ECMWF). The interaction of the stratospheric wind field with upward propagating atmospheric waves leads to a large scale residual circulation in the mesosphere which is upward at high latitude in the summer hemisphere, and downward in the winter hemisphere. It is this residual circulation which leads to the very cold temperatures at the mesopause. More specifically, the change in direction of the stratospheric wind allows upward propagation of the eastward propagating gravity waves which decelerate the westward zonal wind higher in the mesosphere. This change in wind with height must be balanced by decreasing temperatures towards the summer pole (through the thermal wind equation, see e.g. Andrews et al., 1987, p.306). So a fairly close relation between the summer period of westward wind in the stratosphere and the NLC season would be expected.

It is clear in Fig. 2 that the end of the NLC season lies close to, but just before the end of summer in the stratosphere, and that the year to year variation in both is relatively small. The gap between the end of the NLC season and the end of the

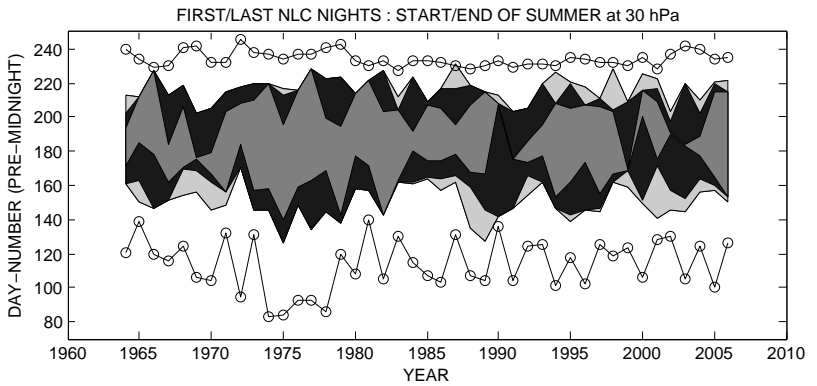

Fig. 2. Comparison of the NLC season (gray areas) with the start and end of summer in the stratosphere (circles/solid lines), defined as the period when the zonal-mean, zonal wind at $60^{\circ} \mathrm{N}$, $30 \mathrm{hPa}$ was consistently directed westward, according to ERA-40 (1664-August 2002) and operational (September 2002-2006) analyses from ECMWF. The shades of grey denote: all NLC reported (light gray), nights where moderate or stronger NLC were reported (black), and nights when bright or very bright displays were reported (dark gray). The gray/black areas are overlaid.

summer zonal wind, averaged over the whole period is 17 days, with standard deviation $\rho 9$ days. There is a much wider gap (35 days, $\rho 16$ days) between the change of zonal wind direction in the stratosphere and the start of the NLC season at the start of summer. The variability of the start of summer $(\rho 15)$ in the stratosphere is higher than for the end of summer ( $\rho 5$ days). For the NLC season the same is true with $\rho 10$ days for the start of the season and $\rho 7$ days for the end, but is less easy to see from the figure. This is to be expected since planetary wave amplitudes are much higher in the winter hemisphere and these strongly affect the transition from winter to summer in both the stratosphere and mesosphere, making it highly variable (see e.g. Salby, 1996, p.556).

In Fig. 2, there seems to be some correspondence between early starts and/or a late ends to summer in the stratosphere between during the 1970s, and simultaneous extensions to the NLC season. Otherwise the variations in the NLC and stratospheric summer seasons do not seem particularly well correlated. Figure 1 shows that the length of the NLC season was relatively short in the years 1964-1972, long from 19731982, and short again since then. So the anomalous period in the NLC, 1973-1982, corresponds rather well to the period of earliest start/latest end for the season in the stratosphere. Using a least-square linear fit it can be shown that, altogether, the variations in the length of summer in the stratosphere can account for only $11 \%$ of the variations in the length of the NLC season (see Table 2). However, this kind of fit does not take account of similarities between adjacent years. This can be seen better using decadal averages.

Figure 3 compares the distribution of NLC reports over the summer for three 10-year periods, 1966-1973, 1973-1982 and 1986-1995. There are clear quasi-10-year periodicities 
Table 1. Average dates (day number) for the start and end of the summer season in the stratosphere $\left(30 \mathrm{hPa}, 60^{\circ} \mathrm{N}\right)$, and the NLC season, for the decades shown. Summer in the stratosphere is defined as the period during which the zonal mean zonal wind is directed towards the west. This has been determined using the ERA40 reanalysis 1964-2002 and operational analyses thereafter (all from European Center for Medium Range Weather Forecasting, ECMWF). Start and end of the NLC season are for all reliable NLC reports, including faint and very faint NLC. Note that the confidence limits given here are the standard errors of the means, not the standard deviation of the distributions.

\begin{tabular}{|c|c|c|c|}
\hline decade & 1964-1973 & 1973-1982 & 1986-1995 \\
\hline start of summer & $119 \pm 5$ & $104 \pm 7$ & $115 \pm 4$ \\
\hline $30 \mathrm{hPa}, 60^{\circ} \mathrm{N}$ & & & \\
\hline start of NLC season & $153 \pm 3$ & $144 \pm 3$ & $147 \pm 4$ \\
\hline end of NLC season & $214 \pm 2$ & $221 \pm 2$ & $217 \pm 3$ \\
\hline end of summer & $236 \pm 2$ & $236 \pm 1$ & $231 \pm 1$ \\
\hline $30 \mathrm{hPa}, 60^{\circ} \mathrm{N}$ & & & \\
\hline $\begin{array}{l}\text { length of summer } \\
30 \mathrm{hPa}, 60^{\circ} \mathrm{N}\end{array}$ & $118 \pm 6$ & $132 \pm 7$ & $116 \pm 4$ \\
\hline length of NLC season & $61 \pm 4$ & $77 \pm 4$ & $70 \pm 4$ \\
\hline
\end{tabular}

in the nights-per-year data series, so averages over complete decades need to be taken. The first and third periods represent shorter NLC seasons and the second period is chosen to represent a decade when the NLC season was mostly long. Note that the first two periods overlap by one year as there is a need to avoid the years 1983-1985 as the number of contributing observers decreased abruptly in 1983 to less than 30 , but grew to over 40 again by 1986 . The period 19861995 is also the latest decade when at least three reporting sites were included north of $58^{\circ}$ latitude, so this is the last period shown in Fig. 3. This is important since NLC are known to retreat towards high latitudes at the end of the season. It is clear in Fig. 3 that there is a real difference in the statistical distributions for the three decades, with a markedly longer season in the decade 1973-1982, due not only to isolated or faint NLC, but to several moderate and bright NLC seen both early (before day 160, or 10 June) and late in the season (after day 213, which is 1 August). It should be noted that the "official" NLC observing period for the meteorological stations extended from day 146 to day 219 from the start in 1964, and this on its own is sufficient to detect most of the differences between the first two decades. However, observers at those stations made hourly reports on tropospheric clouds all year round, so they are likely also to have reported NLC seen earlier and later. The limits for voluntary observations are by their nature, more flexible, but less certain.

Table 1 lists average characteristics concerning the start and end of the season for the same three decades as in Fig. 3. It can be seen that the decade 1973-1982 was characterised by a significantly longer summer season in the stratosphere, and by a longer NLC season, with most of the difference in the start of the season in both cases. This gives us good reason to be confident that the change seen in NLC season length really did happen and was due to changes in the circulation in the middle atmosphere.

The longer summer season in the stratosphere in the 1970s/early 1980s has also been pointed out by Offerman et al. (2004), for slightly lower latitudes $\left(51^{\circ} \mathrm{N}\right)$. That study also found an $8 \%$ increase in the length of the summer from 1988-2002 close to the mesopause (using $\mathrm{OH}$ temperatures from about $87 \mathrm{~km}$ altitude at $51^{\circ} \mathrm{N}, 7^{\circ} \mathrm{W}$ ). The variability in the length of the NLC season (lowest panel of Fig. 1) is too high to be able to say whether this is seen in the present data. Unfortunately, the $\mathrm{OH}$ temperature series does not cover the period of the longest NLC seasons which is identified in the present analysis (1973-1982).

Finally it should be noted that the increase in faint and very faint NLC which is apparent in Fig. 1 from about 1994 onwards, does not correspond to any significant change in the length of the season. If this increase were due to more favourable conditions for NLC we might expect this also to be reflected in a longer season. The lack of any change in the length of the season is reason to be careful in interpreting the apparent increase in faint NLC as geophysical.

\subsection{Quasi-decadal variation}

The $\sim 10$ year variation is examined in Fig. 4 . A decadal variation in NLC numbers has been noted many times, including in NLC datasets from other locations and other epochs (see e.g. Simmons and MacIntosh, 1983; Fogle and Haurwitz, 1966; Gadsden, 1998; Romejko et al., 2003). Some indirect relation with the Sun's $\sim 10$ year activity cycle has usually been suggested, and this is represented by the solar $10.7 \mathrm{~cm}$ radio flux in Fig. 4. As can be discerned from Fig. 4, and has been reported in other studies of recent decades, the correlation is negative (low solar activity correlates with large numbers of NLC) but the high NLC counts lag by about 1 year after solar minimum.

There is significant correlation between the number of NLC nights per year and the solar flux. This applies whether all NLC are included or whether faint ones are excluded, and whether the whole season is considered, or only the core period 20 June-20 July. The best fit lag varies between 1317 months, and the squared correlation coefficients $\left(r^{2}\right)$ from $0.2-0.3$, depending on which of those series is analysed. In other words, $20-30 \%$ of the year to year variation can be statistically explained by the lagged solar flux. No significant correlation between solar flux and the length of the NLC season is found.

Fitting a simple harmonic oscillation with free period has also been tested. For the most reliable time series, the number of NLC nights with displays of moderate or greater brightness, the best-fit sine wave has a period $10.2 \pm 0.8$ years (95\% confidence limits). The best-fit sine-wave to the solar flux series has a period of $10.35 \pm 0.23$ years, so there is no 
Table 2. Results of multi-parameter linear fits to the NLC statistics, excluding nights when only faint or very faint NLC were reported. The fits are to the equation:

$Y=A_{0}+A_{1} \times($ year -1964$)+A_{2} \times\left(F-F_{\text {mean }}\right)+A_{3} \times\left(L-L_{\text {mean }}\right)$,

where $\mathrm{F}$ is the monthly averaged $10.7 \mathrm{~cm}$ solar flux (units $10^{-20} \mathrm{~W} \mathrm{~m}^{-2} \mathrm{~Hz}^{-1}$ ) 15 months before June of the year when the NLC were counted, and L is the length of summer in the stratosphere. The last column shows the square of the correlation coefficient for the final fit. Where fit results are given in italics and parentheses, these were set to zero in the final fit, as they were found to have low statistical confidence. The probability that the coefficients are zero is given by the p-values, for the final fit as a whole, and for the parameters individually.

\begin{tabular}{llllll}
\hline $\mathrm{Y}$ & $\mathrm{A}_{0}$ days & $\mathrm{A}_{1}$ days/year & $\mathrm{A}_{2}$ days/F. & $\begin{array}{l}\mathrm{A}_{3} \\
\text { days/day }\end{array}$ & $\mathrm{r}^{2}$ \\
\hline nights per year & $18.0 \pm 1.8$ & $(0.08 \pm 0.15)$ & $-6.8 \pm 4.0$ & $0.13 \pm 0.11$ & 0.38 \\
May-August & & $p=0.28$ & $\mathrm{p}=0.001$ & $\mathrm{p}=0.003$ & $\mathrm{p}=0.0001$ \\
Length of NLC sea- & $59.3 \pm 4.4$ & $(-0.09 \pm 0.37)$ & $(-2.0 \pm 10.2)$ & $0.31 \pm 0.26$ & 0.12 \\
son (nights) & & $p=0.63$ & $p=0.34$ & $p=0.02$ & $p=0.02$ \\
nights per year & $10.2 \pm 0.9$ & $(0.06 \pm 0.08)$ & $-3.6 \pm 2.0$ & $(0.04 \pm 0.06)$ & 0.24 \\
20 June-20 July & & $p=0.17$ & $p=0.0008$ & $p=0.3$ & $p=0.0008$ \\
\hline
\end{tabular}

statistical basis for preferring the solar flux over a simple harmonic wave, or vice-versa.

It is sometimes assumed that the decadal fluctuations in NLC are caused by a direct effect of increased solar radiation at NLC heights, for example heating effects and photodissociation of water vapour by increased Lyman alpha radiation. However, the lag between the solar radiation changes and the NLC changes suggest that a more indirect mechanism may be operating. It is by now well established that changes in stratospheric circulation occur approximately in phase with the solar cycle (van Loon and Labitzke, 2000) and that these can be reasonably well explained by the changes in ultraviolet radiation from the Sun over the solar cycle and their effects on the stratospheric ozone layer (Matthes et al., 2004). So far, solar cycle effects on atmospheric circulation have only been modelled for the extreme states, i.e. no modelling of the time needed to change from one state to the other has been possible. However, the known interaction of the stratospheric circulation with the equatorial quasi-biennial oscillation (van Loon and Labitzke, 2000), and with stratospheric ozone (Matthes et al., 2004), with a lifetime up to many months, make it likely that there is a considerable delay in the atmosphere's response.

\subsection{Multi-parameter fits}

Now two possible factors have been identified which might reasonably explain at least part of the variability in NLC characteristics from year to year. A reasonable mathematical way in which to test the significance of these two factors, and of possible trends, is to make multi-parameter linear fits, including all 3, to the NLC characteristics in Fig. 1. This analysis is first restricted to the time series excluding faint or very faint NLC, as this is likely the most geophysically representative subset of the data. The results are summarized in
Table 2. In all cases, the lag between solar activity (monthly $10.7 \mathrm{~cm}$ fluxes) and the characteristic to be tested, has been set to 15 months. This has been determined by first stepping the lag in intervals of 1 month, finding the multi-parameter best fit, and calculating the sum of the residuals. Lags between 13 and 17 months all give close to the same residuals for the number of NLC nights each year, whether the whole season is taken or only 20 June-20 July. For the length of the NLC season, there is no statistically significant dependence on solar flux (i.e. $26 \%$ chance that the correlation is zero).

Then, multi-parameter linear fits have been tried with all possible predictors (constant, trend, solar flux with 15 month lag, length of summer in the stratosphere). The MATLAB "stepwise" function was used for this allowing easy interactive swapping of the various predictors in and out of the fit. For the final results shown in the table, only predictors which were significant at the $90 \%$ level were retained. In practice, the parameters excluded from the final fit were very far from this level of significance (see p-values in Table 2). The final fits are illustrated in Fig. 5. Table 2 shows, as might be expected, that the length of summer in the stratosphere is the only significant predictor for the length of the NLC season. The solar flux is the only significant predictor for the number of NLC seen during the core period. Both are significant for the total number of NLCs seen during the season as a whole. No significant trends are found (i.e. there is $17 \%$ or more probability that they are zero).

In Table 3 we show results when we include also nights when only faint NLC were reported. Essentially the same solar cycle dependencies as in Table 2 are found and there is still no trend in the length of the NLC season. There is however a statistically significant increasing trend in the reported number of nights with NLC which amounts to 0.4 nights per year the whole season and 0.2 nights per year for the core 
Table 3. As Table 2 but including all nights when NLC were reported, bright, moderate, faint or very faint.

\begin{tabular}{llllll}
\hline $\mathrm{Y}$ & $\mathrm{A}_{0}$ days & $\mathrm{A}_{1}$ days/year & $\mathrm{A}_{2}$ days/F. & $\mathrm{A}_{3}$ days/day & $\mathrm{r}^{2}$ \\
\hline nights per year & $19.1 \pm 3.8$ & $0.39 \pm 0.17$ & $-11.0 \pm 4.1$ & $(0.16 \pm 0.17)$ & 0.53 \\
May-August & & $p=0.0003$ & $p=0.0006$ & $p=0.06$ & $p=0.0001$ \\
Length of NLC sea- & $67.4 \pm 4.0$ & $(0.05 \pm 0.32)$ & $(-6.4 \pm 8.2)$ & $(0.17 \pm 0.23)$ & 0.003 \\
son (nights) & & $p=0.75$ & $p=0.12$ & $p=0.16$ & \\
nights per year & $11.2 \pm 1.9$ & $0.19 \pm 0.08$ & $-4.3 \pm 2.1$ & $(0.04 \pm 0.07)$ & 0.48 \\
20 June-20 July & & $p=0.0008$ & $p=0.009$ & $p=0.28$ & $p=0.0001$ \\
\hline
\end{tabular}
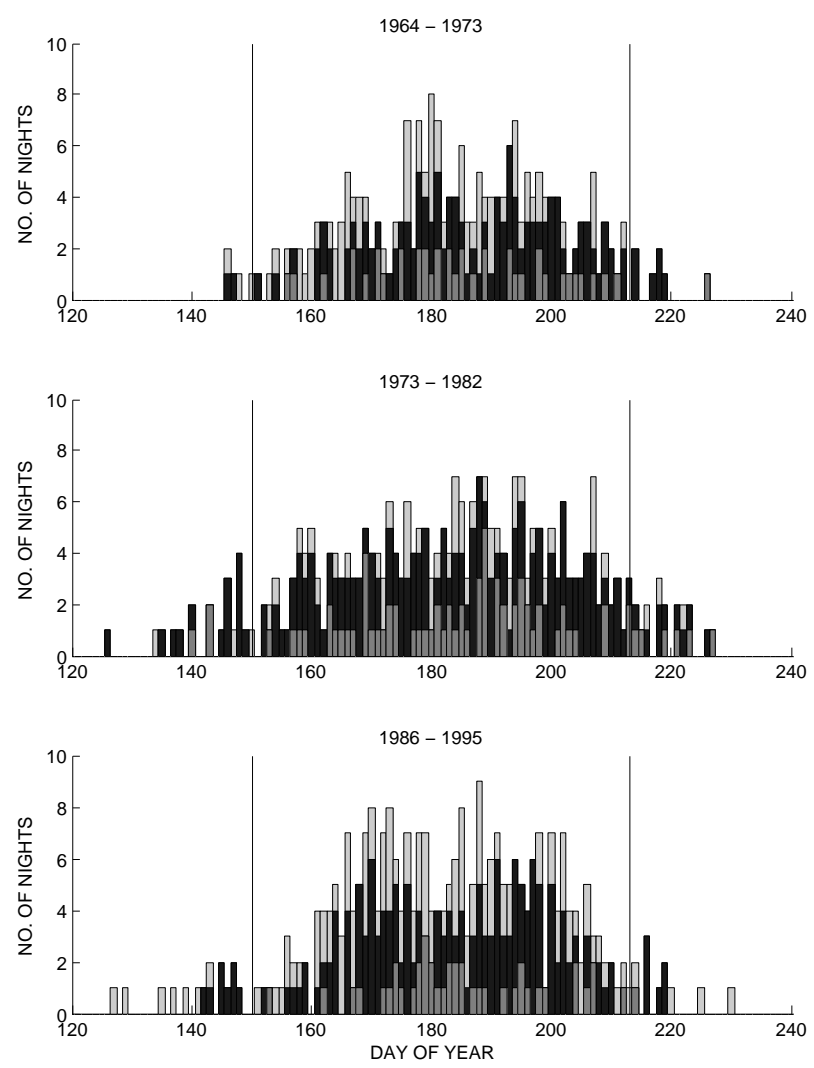

Fig. 3. Histograms of nights of reported NLC as a function of day number for three decades as shown at the top of each panel. The shades of grey denote: all NLC reported (light gray), nights where moderate or stronger NLC were reported (black), and nights when bright or very bright displays were reported (dark gray). The different histograms are overlaid. Vertical lines mark 1 June and 1 August.

period. Whether or not these trends are geophysical or due to changes in observing practices, is discussed below, in the final section of the paper.

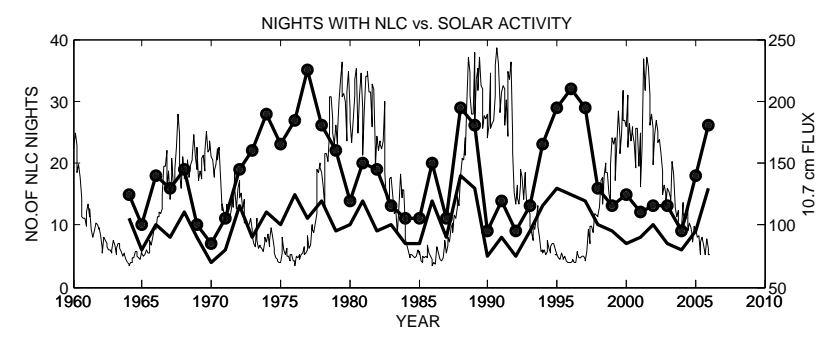

Fig. 4. Comparison of the number of nights with NLC for the whole season (solid dots and thick solid line) and (thick solid line) between 20 June and 20 July each year (excluding faint or very faint NLC) and the monthly average $10.7 \mathrm{~cm}$ solar flux (thin line, right hand axis, units $10^{-22} \mathrm{~W} \mathrm{~m}^{-2} \mathrm{~Hz}^{-1}$ ). These are observed fluxes from Ottawa/Penticon from the National Geophysical Data Center website, www.ngdc.noaa.gov. Annual NLC counts are plotted at the same $\mathrm{x}$-coordinate as the solar flux for the month of July.

\section{Planetary wave signatures}

Figure 6 illustrates the principles of NLC modulation by planetary-waves and tides. Panel (a) shows that case when the mean situation (temperature/water vapour) is slightly below the saturation level, and temperature perturbations from a combination of tides (1-day) and planetary waves (5-day) produce alternating conditions of saturation (black) and nonsaturation (white). In panel (b), the wave perturbations are smaller, and in panel (c) the mean temperature is further below the saturation level. In the final panel (d), amplitude of the planetary wave is decreased. (Note that Fig. 6 is intended only to illustrate the principles of this modulation the real amplitudes of the perturbations are not well known). When the temperature is below saturation for a long time, NLC particles can grow to large size resulting in bright displays. When the temperature is low enough for saturation for only a short time, fainter displays are more likely. When the temperature is above saturation, no NLC will be seen. In situation A, bright NLC are likely to be seen at 5-day intervals. In case B or C they are likely to be seen more often, and at any interval. In case D bright NLC are less likely but faint NLC will be seen more often than in case A. 

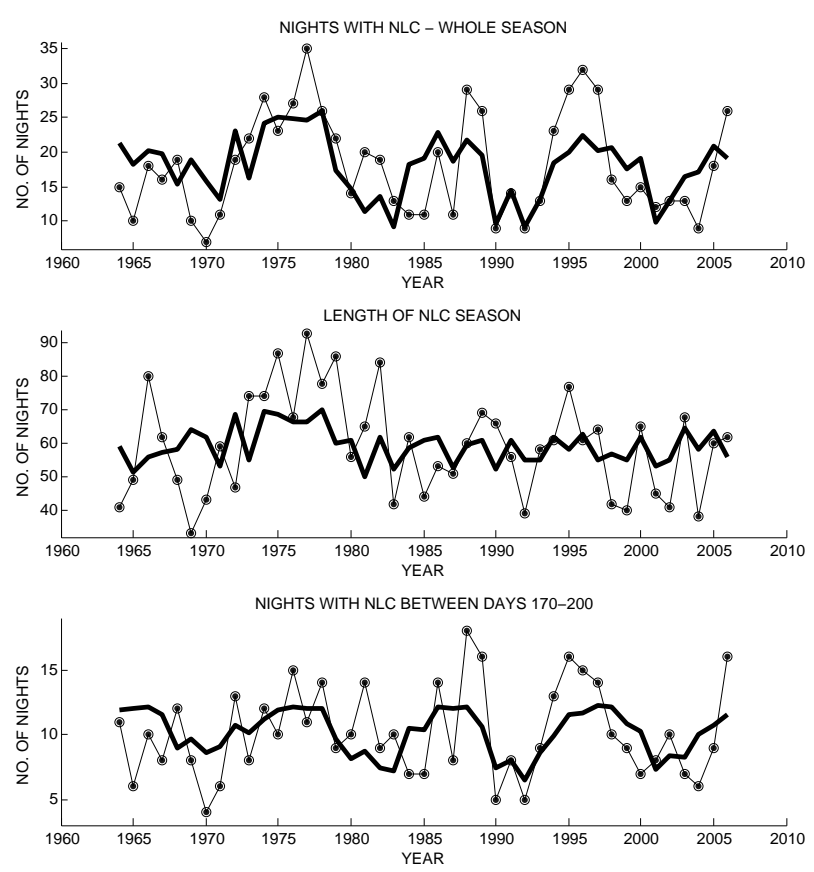

Fig. 5. Year-to-year variations of NLC characteristics (excluding faint or very faint NLC) (solid dots and thin lines) and results of the final multi-parameter fit in Table 2 (thick solid lines). See text for further details.
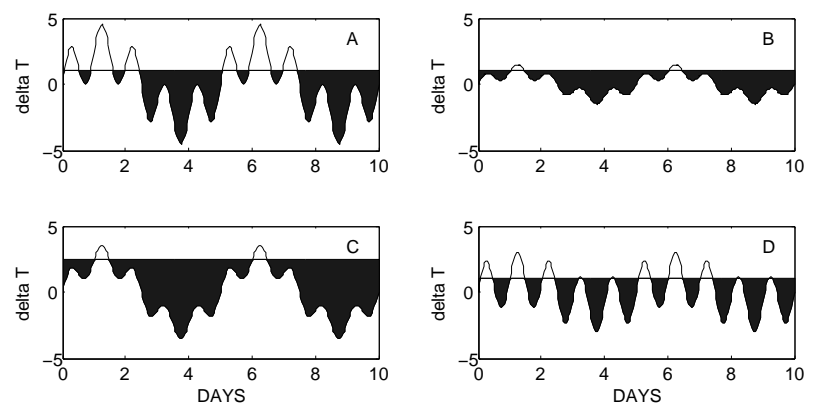

Fig. 6. Principles of NLC modulation by planetary-waves and tides. Panel (A) shows that case when the mean situation (temperature/water vapour) is slightly below the saturation level, and temperature perturbations from a combination of tides (1-day) and planetary waves (5-day) produce alternating conditions of saturation (black) and non-saturation (white). In panel (B), the wave perturbations are smaller, and in panel (C) the mean temperature is further below the saturation level. In panel (D), the amplitude of the planetary wave is decreased, but the tidal amplitude is the same as in (A).

Figure 7 shows histograms of the number of days separating consecutive bright or very bright displays, for 4 decades of the observing period. The first 2 periods overlap by one year, and the years 1983-1985 are omitted, so as to have the
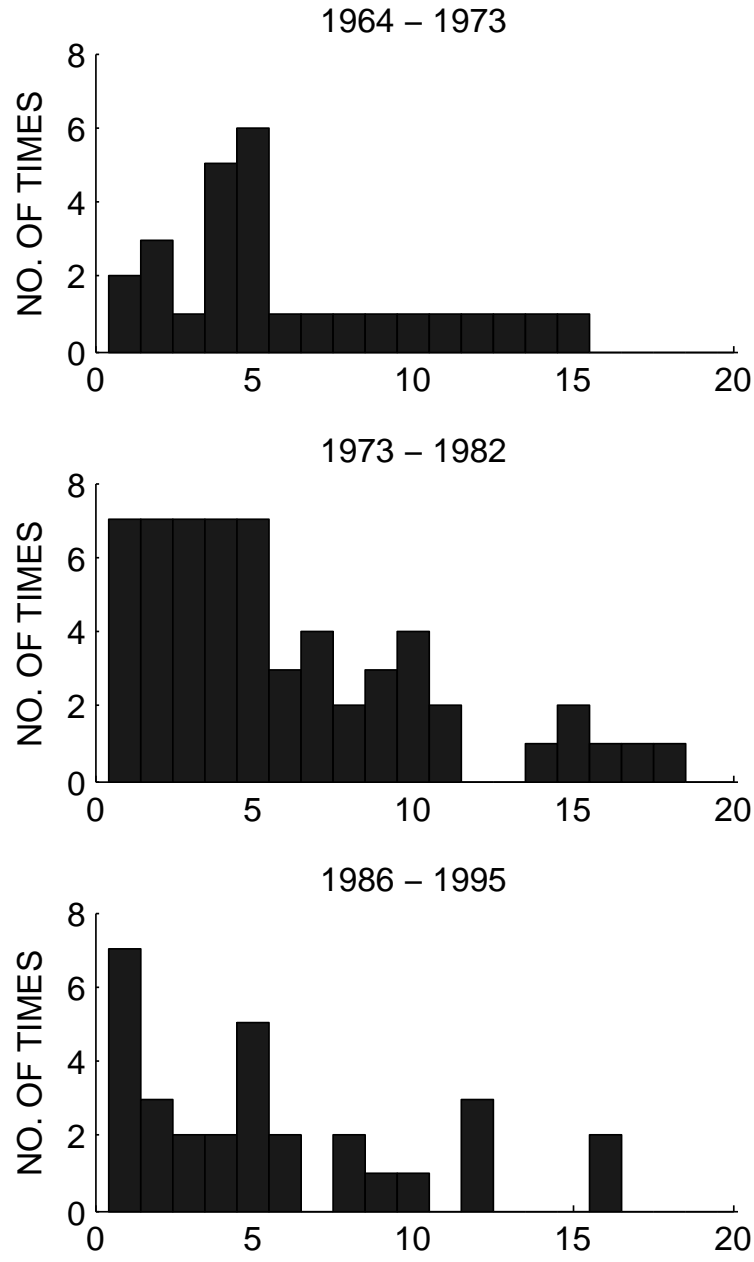

$1996-2005$

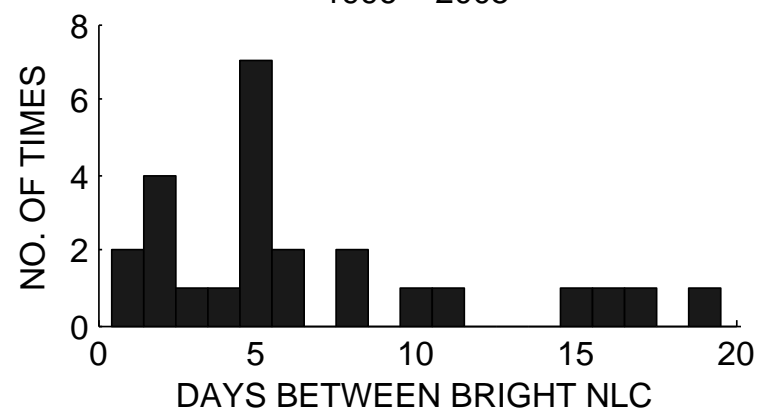

Fig. 7. Histograms of the number of days between consecutive bright or very bright NLC displays, for the decades indicated at the top of the panels.

first three decades the same as in Fig. 3. There is a clear peak at 5 days in 3 of the 4 histograms. This is the same result as reported by Kirkwood and Stebel (2003) where the peak was identified as caused by 5-day planetary waves, and likely corresponds to case (a) in Fig. 6. In the decade 1973- 
1982 there is no peak at 5 days, bright NLC were common, and they appeared with any space between them from 1-5 days. This suggests a situation as in (b) or (c) in Fig. 6, i.e. that the mean conditions during that decade are further from the threshold (lower temperature, higher water vapour) for NLC formation or that the temperature perturbations associated with the 5-day planetary waves and tides are smaller. This fits well with the result in Sect. 3.1 above, that this time interval was anomalous, with a longer NLC season which could be a result of colder mean temperatures or less wave activity.

Finally it can be seen in Fig. 7 that the period 1996-2005 seems to show as much sensitivity to 5-day waves as the first and third decades. However, the numbers of bright NLC in all those decades are small so that it is possible that a combination of situations $\mathrm{A}$ and $\mathrm{C}$ at different times of the season can provide a geophysical explanation for the increase in reports of faint NLC since 1995, without any corresponding increase in brighter NLC.

\section{Summary and conclusions}

The combined UK/Denmark record of noctilucent cloud observations over the period 1964-2006 shows evidence for a significantly longer NLC season from 1973-1982, compared to the rest of the time interval. Corresponding changes in the length of the summer season are also found for the zonalmean zonal winds in the stratosphere. Further, there were more bright or very bright NLC compared to other decades, and less sensitivity to 5-day planetary waves. Lower mean temperatures, and/or higher water vapour and/or smaller planetary wave or tidal amplitudes could explain these results.

The time series of number of NLC nights each year shows a quasi-decadal variation with good anti-correlation with the solar $10.7 \mathrm{~cm}$ flux, with a lag of 13-17 months. Equally close correlations can be found using simple harmonic waves with periods which are not significantly different to that of the $10.7 \mathrm{~cm}$ flux. $20-30 \%$ of the year-to-year variation can be statistically explained by the lagged solar flux, or by the harmonic wave.

No evidence is found for a statistically significant trend in the length of the NLC season, nor in the number of NLCnights each year for displays of moderate or greater brightness. When nights with reports of faint NLC are included, positive trends are found in the numbers of NLC-nights per year.

Multi-parameter linear fits have been made to test the statistical significance of trends, quasi-decadal variations (represented by the solar $10.7 \mathrm{~cm}$ flux, lagged by 15 months) and the length of the summer in the stratosphere, in explaining NLC numbers. For the number of NLC nights between 20 June and 20 July, significant correlation (i.e. less than $5 \%$ chance that the correlation is zero) is found only with the quasi-decadal variation, $\left(r^{2}=0.24\right)$. The length of the NLC season correlates only with the length of summer in the stratosphere $\left(r^{2}=0.12\right)$. NLC nights per year shows significant correlation with both the length of summer in the stratosphere and the quasi-decadal variation. The two factors together can explain $38 \%$ of the year-to-year variation in NLC numbers $\left(r^{2}=0.38\right)$. No statistically confident trend is found in the number of nights with moderate-to-bright NLC where the multi-parameter fit for the whole season gives a trend of 0.08 nights/year with a statistical probability of $28 \%$ that it is zero (and, correspondingly, a $28 \%$ chance that it is as high as 0.16 nights per year). A statistically significant trend is found in the number of NLC nights when reports of faint NLC are included. In this case the multi-parameter fit for the whole season gives a trend of 0.4 nights/year with less than $1 \%$ chance that it is zero.

It is of interest to compare with results for PMC based on satellite measurements. DeLand et al. (2003, 2007) have made detailed analyses of PMC albedo for the period 19792006. Since the satellite data do not cover earlier years than 1979 , there is no possibility to compare our present observation of different characteristics in the decade 1973-1982 compared to earlier or later decades. Regarding the correlation with the solar cycle, the PMC albedo showed a negative correlation with approximate 1-year lag, as do our present NLC occurrence counts. However, whereas the lag in the case of PMC could not be determined to better than $0.5 \pm 1$ year, we find less uncertainty in our NLC results, $15 \pm 2$ months. The solar-cycle effect on PMC albedo was found to be $17 \%$ in average for latitudes $50^{\circ} \mathrm{N}-82^{\circ} \mathrm{N}$, but only $7 \%$ for latitudes $50^{\circ} \mathrm{N}-64^{\circ} \mathrm{N}$, which are the latitudes corresponding to our NLC statistics. The solar cycle effect we find on NLC occurrence rates is much higher, $45 \%-50 \%$. PMC albedo and NLC occurrence rates are not the same parameter, which may be the source of the difference. On the other hand, Kirkwood and Stebel (2003) found a possible effect on NLC of changes in longitudinal position of a quasi-stationary planetary wave over the solar cycle. This mechanism would give large amplitude response in NLC occurrence over a single longitude sector but much less effect when averaged over all longitude sectors, as for the PMC observations. The PMC albedo are found to show a significant positive trend of $16 \%$ on average for latitudes $50^{\circ} \mathrm{N}-$ $82^{\circ} \mathrm{N}, 13 \%$ for latitudes $50^{\circ} \mathrm{N}-64^{\circ} \mathrm{N}$, over the whole period 1979-2006. This would appear to contrast with our finding of no statistically confident trend for moderate-bright NLC occurrence rates. However, largely because of the high yearto-year variability, particularly related to the solar cycle, the uncertainty in the NLC trend estimate is rather large. As pointed out above, there is a $28 \%$ chance that the trend is as high as 0.16 days per year, which would correspond to a $20 \%$ increase over 27 years, consistent with the PMC results.

When nights of faint NLC are included, the trend in occurrence rates becomes rather high at 0.4 nights per year for the whole season, half as much for the core season. Since we find 
no corresponding trend in the length of the season, nor trends in the number of moderate or bright displays, nor is any trend discernible in the sensitivity to planetary waves, we must consider whether this is an artefact of observing practices rather than a geophysical effect. We can also consider that the trends, 0.2 or 0.4 nights/year would correspond to $48 \%$ or $57 \%$ increases over 27 years, which is much higher than reported for the PMC albedo trend by DeLand et al. (2007). All these factors give reason to doubt the geophysical significance of the increase in reported faint NLC which may instead be due to increasing skill on the part of the observers in identifying faint NLC. The possibility remains, however, that this increase has a geophysical origin.

Acknowledgements. Particular thanks are due to the late M. Gadsden, whose enthusiasm and energy inspired so many to take an interest in noctilucent clouds. We also thank the many observers who dedicate their summer nights to watching the sky - without their efforts this study would not have been possible. The efforts of the collators (D. Gavine, T. McEwen, K. Kennedy, H. Andersen, O. Skov Hansen), who assemble the information into a form that is easy to use, and who have provided extra information needed for this manuscript, are particularly appreciated. Thanks also to S. Kirkwood for checking the records in the Balfour Stewart Archive at Aberdeen University.

Topical Editor U.-P. Hoppe thanks two anonymous referees for their help in evaluating this paper.

\section{References}

Andrews, D. G., Holton, J. R., and Leovy, C. B.: Middle Atmosphere Dynamics, 489 pp., Academic, San Diego, Calif., 1987.

Dalin, P., Kirkwood, S., Andersen, H., Hansen, O., Pertsev, N., and Romejko, V.: Comparison of long-term Moscow and Danish NLC observations: statistical results, Ann. Geophys., 24, 28412849, 2006,

http://www.ann-geophys.net/24/2841/2006/.

DeLand, M. T., Shettle, E. P., Thomas, G. E., and Olivero, J. J.: Solar backscattered ultraviolet (SBUV) observations of polar mesospheric clouds over two solar cycles, J. Geophys. Res., 108(D8), 8445, doi:10.1029/2002JD002398, 2003.

DeLand, M. T., Shettle, E. P., Thomas, G. E., and Olivero, J. J.: Latitude-dependent long-term variations in polar mesospheric clouds from SBUV version 3 PMC data, J. Geophys. Res., 112, D10315, doi:10.1029/2006JD007857, 2007.

Fiedler, J., Baumgarten, G., and von Cossart, G.: Mean diurnal variations of Noctilucent clouds during 7 years of lidar observations at ALOMAR, Ann. Geophys., 23, 1175-1181, 2005, http://www.ann-geophys.net/23/1175/2005/.

Fogle, B. and Haurwitz, B.: Noctilucent clouds, Space Sci. Rev., 6, 278-340, 1966.

Gadsden, M.: Observations of noctilucent clouds from North-West Europe, Ann. Geophys., 3, 119-126, 1985, http://www.ann-geophys.net/3/119/1985/.

Gadsden, M.: A secular change in noctilucent cloud occurrence, J. Atmos. Terr. Phys., 52, 247-251, 1990.

Gadsden, M.: The North-West Europe data on noctilucent clouds: A survey, J. Atmos. Sol-Terr. Phy., 60, 1163-1174, 1998.
Gadsden, M.: Frontispiece, in: Mesospheric Clouds 2002: Papers given at the meeting in Perth, Scotland, 19-22 August 2002, edited by: Gadsden, M. and James, N. D., Memoirs of the British Astronomical Association, vol. 45, 2002a.

Gadsden, M.: Statistics of the annual counts of nights on which NLCs were seen, in: Mesospheric Clouds 2002: Papers given at the meeting in Perth, Scotland, 19-22 August 2002, edited by: Gadsden, M. and James, N. D., Memoirs of the British Astronomical Association, vol. 45, 2002b.

Gadsden, M. and Schröder, W.: Noctilucent Clouds, 148 pp., Springer- Verlag, New York, 1989.

Gavine, D. M.: Noctilucent clouds over Western Europe during 1983, Meteorol. Mag., p.113, 1984.

Gavine, D. M.: Noctilucent clouds over Western Europe during 1984, Meteorol. Mag., p.114, 1985.

Gavine, D. M.: Noctilucent clouds over Western Europe during 1985, Meteorol. Mag., p.115, 1986.

Gavine, D. M.: Noctilucent clouds over Western Europe during 1986, Meteorol. Mag., p.116, 1987.

Gavine, D. M.: Noctilucent clouds over Western Europe during 1987, Meteorol. Mag., p.117, 1988.

Gavine, D. M.: Noctilucent clouds over Western Europe during 1988, Meteorol. Mag., p.118, 1989.

Gavine, D. M.: Noctilucent clouds over Western Europe during 1989, Meteorol. Mag., p.119, 1990.

Gavine, D. M.: Noctilucent clouds over Western Europe during 1990, Meteorol. Mag., p.120, 1991.

Gavine, D. M.: Noctilucent clouds over Western Europe during 1991, Meteorol. Mag., p.121, 1992.

Gavine, D. M., Noctilucent clouds over Western Europe during 1992, Meteorol. Mag., 122, 1993.

Gavine, D.: Noctilucent clouds over Britain and Western Europe, 1992-1994, J. British Astron. Assoc., 106, 285-286, 1996.

Gavine, D.: Noctilucent clouds over Britain and Western Europe, 1995-1997, J. British Astron. Assoc., 110, 218-220, 2000.

Gavine, D.: Noctilucent clouds over Britain and Western Europe, 1998-2000, J. British Astron. Assoc., 116, 3-4, 2006.

Gore, A.: Earth in the Balance: Ecology and the Human Spirit, Houghton-Mifflin, N.Y., 368 pp., 1992.

Kirkwood, S. and Réchou, A.: Planetary-wave modulation of PMSE, Geophys. Res. Lett., 25, 4509-4512, 1998.

Kirkwood, S., Barabash, V., Brändström, B. U. E., Moström, A., Stebel, K., Mitchell, N., and Hocking, W.: Noctilucent clouds, PMSE and 5-day planetary waves: A case study, Geophys. Res. Lett., 29(10), 1411, doi:10.1029/001GL014022, 2002.

Kirkwood, S. and Stebel, K.: The influence of planetary waves on noctilucent cloud occurrence over NW Europe, J. Geophys. Res., 108(D8), 8440, doi:10.1029/2002JD002357, 2003.

Matthes, K., Langematz, U., Gray, L. J., Kodera, K., and Labitzke, K.: Improved 11-Year Solar Signal in the Freie Universität Berlin Climate Middle Atmosphere Model (FUB-CMAM), J. Geophys. Res., 109, D06101, doi:10.1029/2003JD004012, 2004.

McIntosh, D. H. and Hallissey, M.: Noctilucent clouds over Western Europe during 1973, Meteorol. Mag., p.103, 1974.

McIntosh, D. H. and Hallissey, M.: Noctilucent clouds over Western Europe during 1974, Meteorol. Mag., p.104, 1975.

McIntosh, D. H. and Hallissey, M.: Noctilucent clouds over Western Europe during 1975, Meteorol. Mag., p.105, 1976.

McIntosh, D. H. and Hallissey, M.: Noctilucent clouds over West- 
ern Europe during 1976, Meteorol. Mag., p.106, 1977.

McIntosh, D. H. and Hallissey, M.: Noctilucent clouds over Western Europe during 1977, Meteorol. Mag., p.107, 1978.

McIntosh, D. H. and Hallissey, M.: Noctilucent clouds over Western Europe during 1978, Meteorol. Mag., p.108, 1979.

McIntosh, D. H. and Hallissey, M.: Noctilucent clouds over Western Europe during 1979, Meteorol. Mag., p.109, 1980.

McIntosh, D. H. and Hallissey, M.: Noctilucent clouds over Western Europe during 1980, Meteorol. Mag., p.110, 1981.

McIntosh, D. H. and Hallissey, M.: Noctilucent clouds over Western Europe during 1981, Meteorol. Mag., p.111, 1982.

McIntosh, D. H. and Hallissey, M.: Noctilucent clouds over Western Europe during 1982, Meteorol. Mag., p.112, 1983.

Merkel, A. W., Thomas, G. E., Palo, S. E., and Bailey, S. M.: Observations of the 5-day planetary wave in PMC measurements from the Student Nitric Oxide Explorer Satellite, Geophys. Res. Lett., 30(4), doi:10.1029/2002GL016524, 2003.

Offermann, D., Donner, M., Knieling P., and Naujokat, B.: Middle atmosphere temperature trends and the duration of summer, J. Atmos. Sol-Terr. Phy., 66, 437-450, 2004.

Paton, J.: Noctilucent clouds in 1964, Meteorol. Mag., 94, 180-184, 1965.

Paton, J.: Noctilucent clouds over Western Europe during 1965, Meteorol. Mag., p.94, 1966.

Paton, J.: Noctilucent clouds over Western Europe during 1966, Meteorol. Mag., p.95, 1967.

Paton, J.: Noctilucent clouds over Western Europe during 1967, Meteorol. Mag., p.96, 1968.

Paton, J.: Noctilucent clouds over Western Europe during 1968, Meteorol. Mag., p.97, 1969.

Paton, J., Noctilucent clouds over Western Europe during 1969, Meteorol. Mag., 98, 1970.

Paton, J.: Noctilucent clouds over Western Europe during 1970, Meteorol. Mag., p.99, 1971.
Paton, J.: Noctilucent clouds over Western Europe during 1971, Meteorol. Mag., p.100, 1972.

Paton, J.: Noctilucent clouds over Western Europe during 1972, Meteorol. Mag., p.101, 1973.

Romejko, V. A., Dalin, P. A., and Pertsev, N. N.: Forty years of noctilucent cloud observations near Moscow: database and simple statistics, J. Geophys. Res., 108(D8), 8443, doi:10.1029/2002JD002364, 2003.

Salby, M. L.: Fundamentals of Atmospheric Physics, Academic Press, 622 pp., 1996.

Shettle, E. P., Thomas, G. E., Olivero, J. J., Evans, W. F. J., Debrestian, D. J., and Chardon, L.: Three-satellite comparison of polar mesospheric clouds: Evidence for long-term change, J. Geophys. Res. 107(D12), 4134, doi:10.1029/2001JD000668, 2002.

Simmons, D. A. R. and McIntosh, D. H.: An analysis of noctilucent cloud over western Europe during the period 1966-1982, Meteorol. Mag. 112, 289-298, 1983.

Thomas, G. E., Olivero, J. J., Jensen, E. J., Schroeder, W., and Toon, O. B.: Relation between increasing methane and the presence of ice clouds at the mesopause, Nature, 338, 490-492, 1989.

van Loon, H. and Labitzke, K.: The influence of the 11-year solar cycle on the stratosphere below $30 \mathrm{~km}$ : A review, Space Sci. Rev., 94, 259-278, 2000.

von Zahn, U. and Berger, U.: Persistent ice cloud in the midsummer upper mesosphere at high latitudes: Three-dimensional modeling and cloud interactions with ambient water vapor, J. Geophys. Res., 108(D8), 8451, doi:10.1029/2002JD002409, 2003.

von Zahn, U., Baumgarten, G., Berger, U., Fiedler, J., and Hartogh, P.: Noctilucent clouds and the mesospheric water vapour: The past decade, Atmos. Chem. Phys., 4, 2449-2464, 2004, http://www.atmos-chem-phys.net/4/2449/2004/. 